\title{
Raw Score
}

National Cancer Institute

\section{Source}

National Cancer Institute. Raw Score. NCI Thesaurus. Code C159275.

A single score that is derived from a test or an observation and that has not been transformed or altered. 